it is repeatedly stated to be a subgenus only, the species is written Stockoceros conklingi, or in one place $S$. (Tetrameryx) conklingi, and a subfamily Stockocerotinæ is proposed (p. 36) to include the group containing Stockoceros. Evidently the subfamily should be Capromerycinæ, based on the oldest genus, and in no case, according to the rules, can it be based on a subgenus. It might be possible to argue, perhaps, that in spite of his intention, Frick had in fact raised Stockoceros to generic rank by his mode of citation. Should this view prevail, Stockocerotinæ might be retrined.

Another problem relates to the permissible length of generic and subgeneric names. Frick has, for example, a new subgenus Pseudoparablastomeryx. I have for many years followed a suggestion made by an author whose name I have forgotten, that such names should never exceed six syllables. There must be a limit somewhere, and perhaps the six-syllable rule would be acceptable, at least for future proposals,

University of Colorado, T. D. A. CockERELI. Boulder. May 12.

\section{The Number of Discriminable Colours}

ALTHOUGH a calculation of the approximate number of discriminable colours must depend upon the individual concerned, 'normal' persons may be expected to furnish data which agree to the correct order of magnitude. The method used here involves the choice of an arbitrary colour solid, the well-known Titchener Ebbinghaus double pyramid, to which available experimental data are applied with simplifying assumptions, in order that ordinary geometry may be used in the calculations. A straight line connecting the apexes of this double pyramid represents the black-white, or brilliance series; the saturation series is represented by lines running from the central axis to the surface; and the hue series is given by lines on the surface of the figure parallel to the base.

The observations of König ${ }^{1}$, ranging from threshold to blinding intensity, give 660 discrete steps as the length of the brilliance axis. Jones ${ }^{2}$, utilizing the measurements of Steindler, Nutting and himself, found 128 just noticeable chromaticity steps in the spectrum. Smith ${ }^{3}$ obtained 28 hues in the psycho logical purples. For the total number of hues, equivalent to the perimeter of the base, we have 156 . Data for saturation are taken from the incomplete experiments of Geissler ${ }^{4}$, the work being done with coloured papers and covering only certain limited ranges. The results show 90 discrete steps from neutral grey to red. While Geissler did not determine the number of steps to each of the other corners, he measured the relative saturations from which the appropriate data may be computed: yellow, 35; green, 28 ; and blue, 67.

These values indicate that the base of the pyramid, if drawn to scale, could not be represented by conventional geometry. For the degree of approximation required here we may take arithmetical averages. We find 39 hue steps between each corner of the base and 55 saturation steps from the periphery to central grey. We shall assume that the number of hues, a function of the saturation, decreases linearly from periphery to centre, thus giving 78 hues at mean saturation. The number of colours in the base becomes 4,290. This is not the 'area', but the total colour sensations, the spacing of which depends upon location. Since König's results are approximately symmetrical, we may use the ordinary formula for the volume of a double pyramid, and thus we obtain for the number of discriminable colours, to two significant figures, the value $9 \cdot 4 \times 10^{5}$. If a double cone is chosen, the results will be the same.

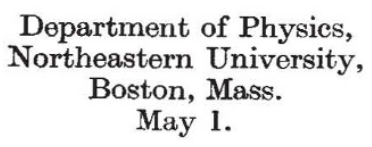

George B. Welch.

${ }^{1}$ König, A., Z. fïr P8ych. u. Physiol. der Sinnesorg., 8, 375 (1895).

${ }^{2}$ Jones, L. A., J. Opt. Soc. Amer., 1, 63 (1917).

${ }^{3}$ Smith, F. O., J. Exper. Psych., 8, 381 (1925).

- Geissler, L. R., Amer. J. Psych., 24, 171 (1913).

\section{An Effect of X-Radiation on the $\zeta$ Potential of Colloidal Graphite}

IN the course of our attempts to elucidate the nature of the action of X-rays on colloids, we have been investigating the effect of irradiation on the $\zeta$ potential of the colloidal particles. The sol selected for the preliminary experiments was an artificial graphite dispersed in conductivity water with the aid of traces of ammonia. This sol is practically homogeneous towards X-radiation, and has a low electrolytic content. It is stable, and the $\zeta$ potential of a given stock shows no significant changes over a period of four months. The $\zeta$ potential is deduced from measurements on the electrophoretic velocity of the particles. The experimental technique employed in our laboratory has been fully described by Lane and White ${ }^{1}$, who have shown that the probable error of a single observation is of the order of $2 \frac{1}{2}$ per cent.

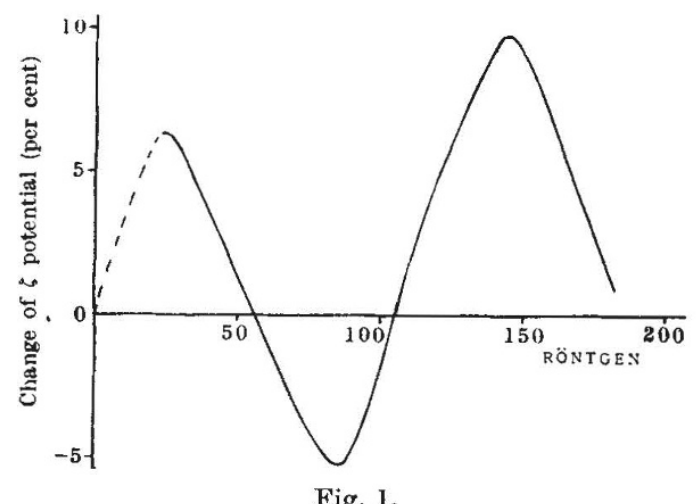

The nature of the results obtained is indicated, for small doses of radiation, in the accompanying graph (Fig. 1). The ordinates represent the percentage change in $\zeta$ potential, the abscissæ the corresponding doses measured in röntgens. It will be seen that a significant increase in the negative $\zeta$ potential is produced by a dose of only $25 \mathrm{r}$., but that the effect is not a monotonic function of the dose. The oscillations persist, with undiminished amplitude, but with increasing wave-length, up to doses of $25,000 \mathrm{r}$. Effects of a similar kind were also obtained with gamma radiation. For one of the sols measured the percentage changes in potential at the first maximum (25 r.), first minimum (85 r.) and second maximum $(143$ r.) were $+(7 \cdot 0 \pm 0 \cdot 6)$ per cent, $-(6 \cdot 0 \pm 0 \cdot 5)$ 